\title{
Effect of Adsorbents on Degradation of Toxic Organic Compounds by Coimmobilized Systems
}

\author{
Ali R. Siahpush,* Jian-Er Lin, and Henry Y. Wang ${ }^{\dagger}$ \\ Department of Chemical Engineering, The University of Michigan, Ann Arbor, \\ Michigan 48109
}

Received June 10, 1991/Accepted September 27, 1991

The use of coimmobilized systems for treatment of toxic organic compounds has been proposed. The proposed approach combines the use of adsorbents and laboratory identified microorganisms immobilized in a protective permeable barrier to achieve a greater degree of control over the remediation process. This study was launched to understand the effect of adsorbents and changes in adsorption on the degradation of toxic compounds by coimmobilized systems. The specific case studied involved the degradation of pentachlorophenol (PCP) by Arthrobacter (ATCC 33790) coimmobilized with powdered activated carbon within calcium alginate capsules.

The design parameters studied included adsorbent content and type as well as the effect of solution $\mathrm{pH}$ and surfactant concentration on adsorption and biodegradation. It was found that the equilibrium adsorption behavior of PCP was strongly influenced by solution $\mathrm{pH}$ and surfactant concentration. A mathematical model was developed that combined the physical processes of mass transfer and adsorption with biological degradation of PCP. The model was used to predict the effect of various parameters on the degradation of PCP. Based on model predictions, the degradation of PCP was strongly dependent on variations in adsorbent capacity and affinity for this contaminant.

Key words: biodegradation - pentachlorophenol - coimmobilization - mathematical modeling $\cdot$ adsorption

\section{INTRODUCTION}

The concept of using coimmobilized systems for the treatment of toxic organic contaminants was introduced by Lin et al ${ }^{8,9}$ This coimmobilization concept combines biologically activated carbon and immobilized cell technology to achieve a greater degree of control over the microenvironment of the organisms used to treat various toxic organic contaminants. Coimmobilization can best be described as the use of microorganisms, with known degradative capabilities, immobilized together with an adsorbent within a spherical permeable gel matrix or membrane.$^{12}$ In order to test this concept, Arthrobacter (ATCC 33790) was coimmobilized with powdered activated carbon in calcium alginate capsules and used to degrade pentachlorophenol (PCP) (Fig. 1). Some of the advantages of coimmobilized systems over cell immobilization include the following: (1) Adsorbents quickly remove the contaminant. This allows high flow rates to

\footnotetext{
* Current address: Michigan Biotechnology Institute, 3900 Collins Road, Lansing, MI 48910.

† To whom all correspondence should be addressed.
}

Biotechnology and Bioengineering, Vol. 39, Pp. 619-628 (1992)

(c) 1992 John Wiley \& Sons, Inc. be used in fluidized or packed beds of coimmobilized systems, hence treating large volumes of contaminated waste and achieving cleaner effluents. (2) The use of adsorbents dampens variations in contaminant concentration when influent concentrations vary and allows for operational stability. (3) Adsorbents help achieve lower concentrations when the contaminant is highly toxic. (4) Adsorbents help to retain any extracellular enzymes that would otherwise be lost. Other advantages of the coimmobilized concept over other conventionally used systems of biologically activated carbon, immobilized cell technology, or simple bioaugmentation (inoculation) are described elsewhere. ${ }^{8,9}$

Adsorbents can control contaminant concentration within coimmobilized systems, thereby influencing contaminant degradation. In order to design coimmobilized systems for the degradation of toxic organic compounds, it is necessary to determine the effect of adsorbents on the degradation of contaminants. In this study, the effect of adsorbent content and type as well as the effect of changes in adsorption behavior on the mineralization of PCP were examined by mathematical modeling. These changes in adsorption behavior were achieved via addition of surfactants or by changes in solution $\mathrm{pH}$. A model was developed to describe the diffusion, adsorption, and degradation of PCP by coimmobilized Arthrobacter (ATCC 33790) in batch aqueous cultures.

\section{MATERIALS AND METHODS}

\section{Assays for Aqueous PCP Concentration and PCP Mineralization}

The assay for aqueous PCP concentration was performed by high-performance liquid chromatography (HPLC) and PCP mineralization was measured by evolution of ${ }^{14} \mathrm{CO}_{2}$ in a $\mathrm{CO}_{2}$ trap as described by Lin et al..$^{10,11}$

\section{Preparation of Coimmobilized Capsules and Encapsulated Activated Carbon}

The seed culture of Arthrobacter (ATCC 33790) was grown in a medium containing PCP-Na $(0.1 \mathrm{~g}), \mathrm{NaNO}_{3}$ $(0.5 \mathrm{~g}), \mathrm{K}_{2} \mathrm{HPO}_{4}(0.6 \mathrm{~g}), \mathrm{KH}_{2} \mathrm{PO}_{4}(0.2 \mathrm{~g}), \mathrm{MgSO}_{4}$. $7 \mathrm{H}_{2} \mathrm{O}(0.1 \mathrm{~g}), \mathrm{NH}_{4} \mathrm{Cl}(0.5 \mathrm{~g})$, and $\mathrm{CaCl}_{2} \cdot 2 \mathrm{H}_{2} \mathrm{O}(0.02 \mathrm{~g})$ 


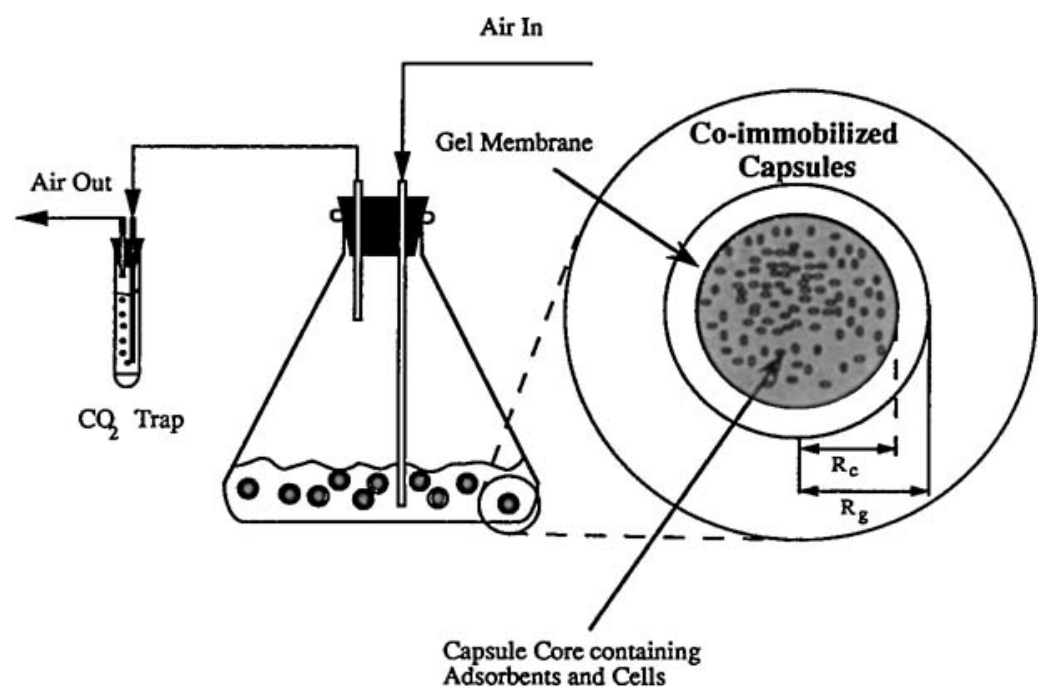

Figure 1. Layout of the apparatus used in the degradation experiments together with a diagram of the coimmobilized capsules.

in $1 \mathrm{~L}$ of distilled water ( $\mathrm{pH} \mathrm{7).} \mathrm{The} \mathrm{culture} \mathrm{was} \mathrm{incu-}$ bated in $100 \mathrm{~mL}$ of medium contained in $500-\mathrm{mL}$ flasks shaken at $80 \mathrm{rpm}$ and $30^{\circ} \mathrm{C}$. To quantify the bacterial cells, aliquots of the culture broth were spread onto tryptic soy agar plates after 3-4 days of incubation. Colonies of Arthrobacter on the agar plates were counted after 3 days of incubation at $30^{\circ} \mathrm{C}^{4}$ One milliliter of the broth with $\mathrm{OD}_{560}$ of 0.23 contained approximately $6 \times$ $10^{5}$ cells. To prepare the coimmobilized capsules, $1.0 \mathrm{~mL}$ of culture broth and $5 \mathrm{mg}$ of powdered activated carbon were mixed with $0.3 \mathrm{M} \mathrm{CaCl}_{2}$ solution to a total of $2.5 \mathrm{~mL}$ (for one flask of degradation mixture). This mixture was then dropped through an air nozzle into a stirred alginate solution $(0.5 \% \mathrm{wt})$. $^{12}$ Mixing was continued for $2 \mathrm{~min}$. The slurry of the formed capsules and alginate solution was then diluted fivefold with distilled water to stop the reaction between $\mathrm{Ca}^{2+}$ and alginate. The capsules were then washed with distilled water.

Encapsulated activated carbon was prepared by the same procedure except the culture broth was replaced by distilled water.

\section{Adsorption Isotherm Determination}

Experiments for determining PCP adsorption isotherms were carried out in $250-\mathrm{mL}$ flasks containing $125 \mathrm{~mL}$ of mineral solution (the growth medium without PCP-Na). The mineral solution was mixed with a stock solution of $776 \mu M$ PCP (Aldrich Co., Milwaukee, WI) achieving different initial PCP concentrations. The PCP stock solution was prepared by dissolving PCP in doubledistilled water and adjusting the $\mathrm{pH}$ with $1 N \mathrm{NaOH}$ to increase PCP solubility. The $\mathrm{pH}$ in the mineral solution was adjusted by addition of $1 N \mathrm{NaOH}$ or $1 N \mathrm{HCl}$ after addition of PCP. Powdered activated carbon $(10 \mathrm{mg}$, Darco G-60, 100 mesh, Aldrich) was added to all flasks. All of the flasks were maintained at $30^{\circ} \mathrm{C}$ on an $80-\mathrm{rpm}$ shaker. Equilibrium was ensured by time course measurements. Experiments with the surfactant Tween 80 were performed equivalently. Tween 80 was added to each flask from a stock solution of $0.2 \%(\mathrm{wt} / \mathrm{vol})$ to achieve desired concentrations.

\section{Batch Adsorption Rate Experiments}

The stock solution (776 $\mu M$ PCP) was added into 250 $\mathrm{mL}$ flasks containing mineral solution $(20 \mathrm{~mL}$ total volume) to desired concentrations. Powdered activated carbon or encapsulated activated carbon was added to each flask to adsorb PCP. All of the flasks were maintained at $30^{\circ} \mathrm{C}$ on an 80 -rpm shaker.

\section{Removal and Mineralization of PCP by Coimmobilized Capsules}

Coimmobilized bacterial capsules prepared according to the above procedure were added to 250 -mL flasks containing the degradation mixture. For determination of $\mathrm{PCP}$ removal, the degradation mixture contained $3 \mathrm{~mL}$ of PCP stock solution and $17 \mathrm{~mL}$ of mineral solution. For determination of mineralization, the PCP stock solution was spiked with ${ }^{14} \mathrm{C}$-PCP (Sigma Chemical Co., St. Louis, MO). Three milliliters of the spiked PCP and $17 \mathrm{~mL}$ of the mineral solution were used as degradation mixture. The initial PCP concentration was $117 \mu M$ in both cases. The total radioactivity contained in the spiked flasks was approximately $6.5 \times 10^{4} \mathrm{dpm}$. All flasks were maintained at $80 \mathrm{rpm}$ and $30^{\circ} \mathrm{C}$ unless otherwise indicated. The ${ }^{14} \mathrm{CO}_{2}$ was trapped in an ethanolamine containing scintillation fluid ${ }^{6}$ and was measured at indicated intervals.

\section{MODEL DEVELOPMENT}

\section{Equilibrium Isotherms}

For the adsorption of PCP onto activated carbon, a reversible Langmuir isotherm was chosen. ${ }^{7}$ This type of 
isotherm was chosen according to the trend observed in the experimental data and is not necessary for model development. Such an analysis leads to the following expression relating the amount of adsorbate bound to the adsorbent, $q$, to the concentration of the same component in solution, $C$, at equilibrium:

$$
q=\frac{q_{\max } C}{K_{d}+C}
$$

where $q_{\max }$ is the maximum capacity of the adsorbent for PCP and $K_{d}$ is the dissociation constant. The changes in equilibrium adsorption behavior as a function of such variables as $\mathrm{pH}$ and surfactant concentration were modeled as changes in $q_{\max }$ and $K_{d}$.

\section{Mass Transfer and Adsorption Rate}

The migration of PCP in a batch liquid phase system to which a certain quantity of coimmobilized capsules have been added can be described mathematically using the following assumptions:

1. The transfer of products between the bulk solution and the capsule membrane is assumed to occur across a thin hydrodynamic film.

2. All components have constant effective diffusivities within any one phase, the value of which is independent of concentration.

3. The adsorbent particles and the cells are assumed to be infinitely small and evenly distributed within the capsule core.

4. Compared to the adsorbent, the adsorption of PCP onto the gel membrane can be neglected.

5. The bulk solution is perfectly mixed.

6. The degradation product, mainly carbon dioxide, does not adsorb onto the adsorbent.

7. The rate of adsorption of PCP can be described by a second-order surface reaction model that at equilibrium produces the Langmuir isotherm.

The following equations describe the concentration of various species in the bulk solution, gel membrane, and capsule core, respectively:

$$
\begin{gathered}
\frac{d C_{b i}}{d t}=-\frac{3 V_{A} K_{c}}{R_{g} V_{b}}\left(C_{b i}-C_{i\left(R=R_{g}\right)}\right) \\
\varepsilon_{g i} \frac{\partial C_{i}}{\partial t}=\varepsilon_{g i} D_{g i}\left(\frac{\partial^{2} C_{i}}{\partial R^{2}}+\frac{2 \partial C_{i}}{R \partial R}\right) \\
\varepsilon_{c i} \frac{\partial C_{i}}{\partial t}=\varepsilon_{c i} D_{c i}\left(\frac{\partial^{2} C_{i}}{\partial R^{2}}+\frac{2 \partial C_{i}}{R \partial R}\right)+R_{\mathrm{ads}}+\sum_{l=1}^{n} R X N_{l}
\end{gathered}
$$

where $R_{\text {ads }}$ is the rate of adsorption of species $i$, and $R X N_{l}$ is the various biological reactions in which species $i$ is involved. According to the second-order rate of adsorption model, the adsorption rate is given by the expression

$$
R_{\text {ads }}=-\rho_{g} \frac{d q_{i}}{d t}=-\rho_{g}\left(\kappa_{1} C_{i}\left(q_{\max }-q_{i}\right)-\kappa_{1} K_{d} q_{i}\right)
$$

Equation (5) results in a Langmuir isotherm at equilibrium. The variable $\kappa_{1}$ is the rate constant for the forward rate of adsorption, and $K_{d}$ is the dissociation constant.

The corresponding initial and boundary conditions are

$$
\begin{gathered}
{\left[\frac{\partial C_{i}}{\partial R}\right]_{R=0}=0} \\
-D_{g i}\left[\frac{\partial C_{i}}{\partial R}\right]_{R=R_{c}+}=-D_{c i}\left[\frac{\partial C_{i}}{\partial R}\right]_{R=R_{c}-} \\
{\left[\frac{\partial C_{i}}{\partial R}\right]_{R=R_{g}}=\frac{K_{c i}}{\varepsilon_{g i} D_{g i}}\left(C_{b i}-C_{i\left(R=R_{g}\right)}\right)} \\
{\left[C_{b i}\right]_{l=0}=C_{b i}(0)} \\
{\left[C_{i}\right]_{0 \leq R \leq R_{g}}=0 \quad \text { at } t=0}
\end{gathered}
$$

\section{Biodegradation}

Since the cells are trapped within the core and cannot diffuse through the gel membrane, the cell concentration only need be described within the core and can be assumed to be zero elsewhere. It is further assumed that the cells are stationary and do not diffuse in space within the core. The concentration of the cells within the core can be described by the following equation:

$$
\begin{array}{cl}
\frac{d X}{d t}=R X N_{x} & 0 \leq R \leq R_{c} \\
X=0 & R>R_{c}
\end{array}
$$

With the following initial condition:

$$
[X]_{0 \leq R \leq R_{c}}=X_{0} \text { at } t=0
$$

If the conversion of PCP to $\mathrm{CO}_{2}$ by Arthrobacter can be described by a one-step process, neglecting the conversion of PCP into various metabolic intermediates, the mineralization of PCP may be described by the following equation:

$$
R X N_{\mathrm{PCP}}: \quad \frac{d C_{\mathrm{PCP}}}{d t}=\frac{1}{Y_{x / C}} \mu X=-K_{1} C_{\mathrm{PCP}} X
$$

This is obviously an oversimplification of the fate of PCP and does not consider multiple dechlorination steps and ring cleavage that PCP must undergo before conversion to carbon dioxide. The description of PCP degradation by first-order kinetics is expected to yield reasonable results only at low PCP concentrations. A more accurate description of the fate of PCP would require a detailed study. Assuming that the fate of PCP is adequately described by the above expression, the cell density and $\mathrm{CO}_{2}$ concentration can be related to $\mathrm{PCP}$ concentration by the equations

$$
R X N_{X}: \quad \frac{d X}{d t}=\mu X=K_{2} C_{\mathrm{PCP}} X
$$

$$
R X N_{\mathrm{CO}_{2}}: \quad \frac{d C_{\mathrm{CO}_{2}}}{d t}=Y_{\mathrm{CO}_{2} / x} \mu X=K_{3} C_{\mathrm{PCP}} X
$$


where $\mu$ is the growth rate, $X$ is the cell concentration, and $Y_{x / c}$ and $Y_{\mathrm{CO}_{2} / x}$ are the corresponding yield factors. The product formation model above is the LeudekingPiret kinetic model, ${ }^{1}$ without the maintenance and death term, typically used when product formation is a result of energy forming metabolism. The PCP utilization equation accounts for conversion of PCP to product as well as utilization for cell growth. Under low PCP concentrations $(\leq 100 \mu \mathrm{M})$, the growth rate was adequately described by first-order kinetics (data not shown):

$$
\mu=K_{\text {growth }} C_{\text {PCP }}
$$

The above equations were solved by a semi-implicit finite difference method as illustrated by Carnahan. ${ }^{2}$

\section{ESTIMATION OF MODEL PARAMETERS}

The value of the dissociation constant and adsorbent maximum capacity were calculated from experimental adsorption isotherms. ${ }^{5}$ This involved linearization of the Langmuir equation and the use of least squares techniques to fit the linearized form of the equation to experimental data. The forward adsorption rate constant was obtained from adsorption experiments performed with free activated carbon at constant $\mathrm{pH}$ and zero surfactant concentration. The dissociation constant and capacity obtained experimentally were assumed to remain constant at constant $\mathrm{pH}$ and surfactant concentration. These values were then used in Equation (5) and solved simultaneously with a batch material balance equation:

$$
V_{B} \frac{d C}{d t}=-W_{A} \frac{d q}{d t}
$$

where $V_{B}$ and $W_{A}$ are the solution volume and adsorbent weight, respectively; $C$ and $q$ are the concentration of PCP in solution and in the adsorbent. The forward adsorption rate constant was held as an adjustable parameter in the model and computed from the best fit produced using a parameter estimation method. ${ }^{5,13}$ The resulting value of $\kappa_{1}$ was estimated to be $0.05(\mathrm{~mL} / \mathrm{g} \cdot \mathrm{h})$. It was assumed that the rates of PCP adsorption and desorption were indistinguishable. The time constant for the mineralization process $(50 \mathrm{~h})$ was approximately two orders of magnitude larger than the adsorption time constant (30 $\mathrm{min}$ ) (data not shown). With such a difference between the two time constants, a $100 \%$ error in adsorption rate coefficient results in a $1.3 \%$ variation in PCP mineralization in $200 \mathrm{~h}$. Furthermore, the assumption was made that immobilized activated carbon behaved equivalently to free activated carbon. Experiments previously performed in our laboratory indicate that compared to the degradation rate of $\mathrm{PCP}$, the rates of adsorption and desorption of PCP from activated carbon are sufficiently similar to justify this assumption. Immobilization of activated carbon did not alter its capacity or affinity for PCP significantly. It was also found that approximately $70 \%$ of the PCP was reversibly adsorbed.

The porosity $(\varepsilon)$ of the capsule membrane was estimated from the alginate content to be $0.98,{ }^{5}$ while the diffusivity of $\mathrm{PCP}$ in solution $(D)$ was calculated from the Wilke-Chang equation to be $7 \times 10^{-6} \mathrm{~cm}^{2} / \mathrm{s}$. This diffusivity value compares well with the measured diffusivities of similar molecules in water. ${ }^{14}$ The relatively small molecular size for PCP and the high porosity of the alginate gel indicate that little error can be expected by estimating the diffusivity of PCP within the gel $\left(D_{g}\right)$ to be equal to $6.86 \times 10^{-6} \mathrm{~cm}^{2} / \mathrm{s}$ from the relation $(D \varepsilon /$ tortuosity $=D_{g}$ ) and by estimating a value of 1 for the tortuosity of alginate. Furthermore, the low density of adsorbents within the core $\left(\rho_{g} \approx 0.008 \mathrm{~g} / \mathrm{mL}\right)$ and low cell density $\left(\mathrm{OD}_{560} \approx 0.093\right)$ provide little resistance to the diffusion of PCP within the core. This suggests that the diffusivity of PCP within the core $\left(D_{c}\right)$ will be close to its free solution diffusivity of $7 \times 10^{-6} \mathrm{~cm}^{2} / \mathrm{s}$. The diffusion coefficients for carbon dioxide in the gel membrane and the capsule core were obtained from the free solution diffusivity by the same estimation. A parameter sensitivity analysis was carried out (results not shown) to ensure that the solutions were stable to small variations in the above estimated parameters. "Stable" is here defined as a variation in the estimated parameter $( \pm 50 \%)$ producing a variation of equal or smaller magnitude in the solution.

Following the verification of the model in predicting adsorption data, Equations (14)-(16) were solved by a semi-implicit Runge-Kutta algorithm equipped with an optimization routine. The optimization routine employed the Gauss-Newton method to minimize the sum of the square of the deviations between model predictions and experimental data obtained from free cells by adjusting the kinetic parameters. ${ }^{3}$ The parameters $\left(K_{\text {growth }}=K_{2}\right)$ and the rate constants for PCP utilization and degradation $K_{1}$ and $K_{3}$ calculated by this method are listed in Table $\mathbf{I}$.

\section{COMPARISON OF MODEL WITH EXPERIMENTAL DATA}

\section{Adsorption Isotherms}

The adsorption isotherms for PCP on activated carbon as a function of solution $\mathrm{pH}$ are displayed in Figure 2, while the variations in the isotherm as a function of Tween 80 concentration are displayed in Figure 3. Large differences were observed in the equilibrium isotherm as a function of $\mathrm{pH}$ and Tween 80 concentration. The exact mechanism behind such differences was not investigated. The isotherm parameters $q_{m}$ and $K_{d}$ for the different data sets are listed in Table II. The Langmuir isotherms fit experimental data relatively well under the conditions examined.

We speculate that the differences observed as a function of $\mathrm{pH}$ are likely due to changes in the distribution 
Table I. Measured variables and estimated parameters used in mathematical model to simulate experimental data.

\begin{tabular}{lll}
\hline \multicolumn{1}{c}{ Parameter } & Value & \multicolumn{1}{c}{ Units } \\
\hline$D_{b}(\mathrm{PCP})=D_{c}(\mathrm{PCP})$ & $7 \times 10^{-6}$ & $\mathrm{~cm}^{2} / \mathrm{s}$ \\
$D_{g}(\mathrm{PCP})$ & $6.86 \times 10^{-6}$ & $\mathrm{~cm}^{2} / \mathrm{s}$ \\
$D_{b}\left(\mathrm{CO}_{2}\right)=D_{\mathrm{c}}\left(\mathrm{CO}_{2}\right)$ & $1.96 \times 10^{-5}$ & $\mathrm{~cm}^{2} / \mathrm{s}$ \\
$D_{g}\left(\mathrm{CO}_{2}\right)$ & $1.94 \times 10^{-5}$ & $\mathrm{~cm} / \mathrm{s}$ \\
$\kappa_{1}$ & 0.05 & $\mathrm{~mL} / \mathrm{g} \cdot \mathrm{h}$ \\
$K_{2}=K_{\text {growth }}$ & $4 \times 10^{-4}$ & $\mathrm{~mL} / \mu \mathrm{mol} \cdot \mathrm{h}$ \\
$K_{1}$ & 3.4 & $1 / \mathrm{OD}_{560} \cdot \mathrm{h}$ \\
$K_{3}$ & 2.8 & $\mathrm{~mol}\left(\mathrm{CO}_{2}\right) / \mathrm{mol}(\mathrm{PCP}) \cdot \mathrm{OD}_{560} \cdot \mathrm{h}$ \\
$R_{g}$ & $3000 \pm 200$ & $\mu \mathrm{m}$ \\
$R_{g}-R_{c}$ & 200 & $\mu \mathrm{m}$ \\
\hline $\mathrm{OD}_{560}=0.23$ is equivalent to $6 \times 10^{5} \mathrm{cells} / \mathrm{mL}$. &
\end{tabular}

of PCP between the ionic phenolate form and the uncharged form as the solution $\mathrm{pH}$ approaches the $\mathrm{p} K_{a}$ of PCP (4.75). The uncharged molecule predominates at lower $\mathrm{pH}$ and has a higher affinity for adsorption on

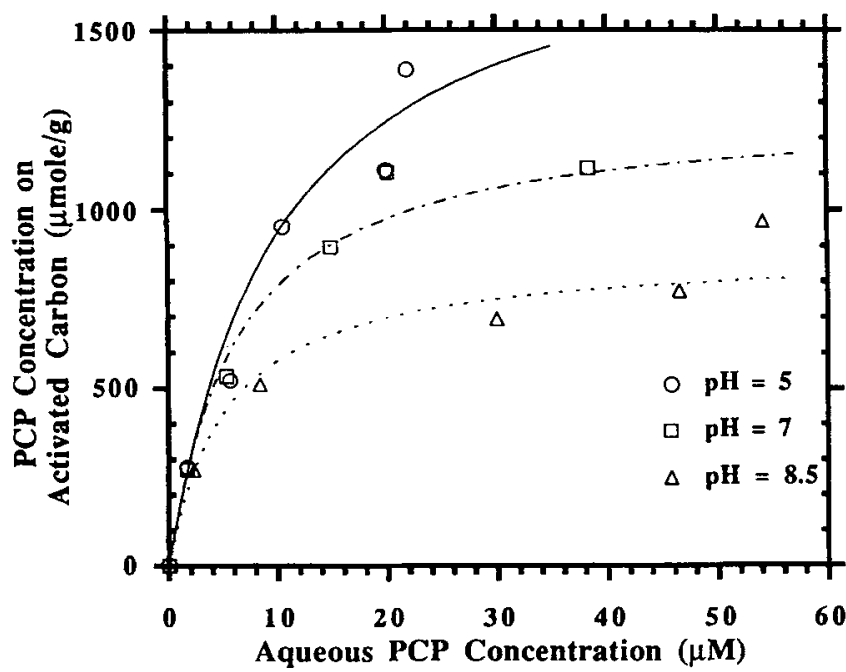

Figure 2. PCP adsorption isotherms on activated carbon as a function of $\mathrm{pH}$.

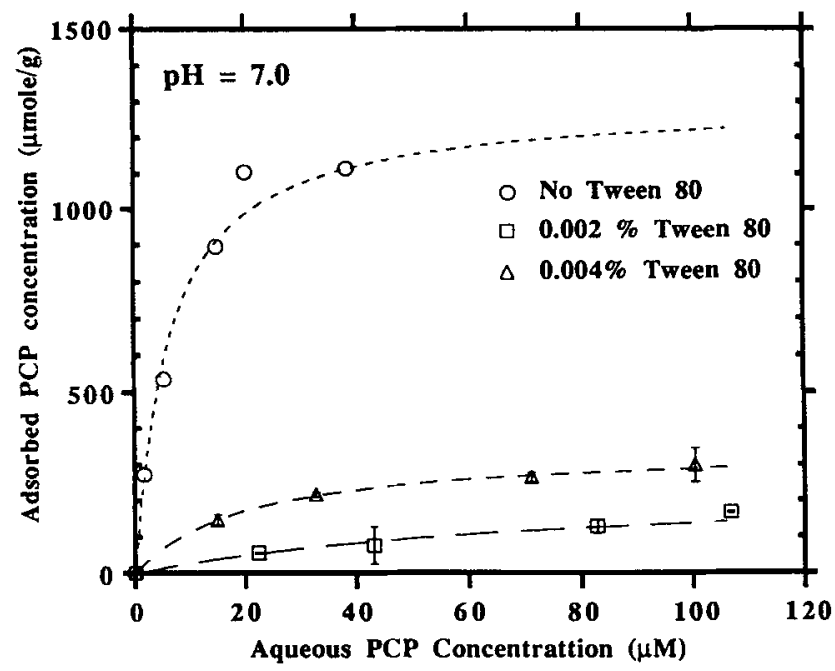

Figure 3. PCP adsorption isotherms on activated carbon as a function of Tween 80 concentration, $\mathrm{pH} 7.0$. activated carbon. It is also possible that at higher $\mathrm{pH}$ values changes in the adsorbent itself can account for variations in adsorption behavior. We speculate that the variations in adsorption behavior observed by addition of Tween 80 were due to the partitioning of PCP in surfactant micelles formed in solution, thus lowering the apparent capacity of activated carbon. The mechanism for an increase in PCP adsorption due to an increase in Tween 80 concentration from 0.002 to $0.004 \% \mathrm{wt} / \mathrm{vol}$ needs to be further investigated.

\section{Batch Kinetic Adsorption Rates}

Experimental rates of PCP adsorption by free and encapsulated activated carbon are compared with simulation results in Figure 4. The capsule size and the membrane thickness were measured by visual inspection via an optical microscope. The simulation results fit experimental data for values of external mass transfer coefficient $\left(K_{c} \geq 5 \times 10^{-3} \mathrm{~cm} / \mathrm{s}\right)$ with progressively worse fit as $K_{c}$ decreased, exhibiting negligible film resistance.

\section{Biodegradation of PCP}

A comparison of PCP removal and mineralization with the simulation results is shown in Figure 5. Removal, in all figures, refers to aqueous PCP concentration, while PCP mineralization or PCP mineralized refers to PCP equivalents converted to $\mathrm{CO}_{2}$. The cell concentration is not displayed in Figure 5 since the cell concentration in

Table II. Langmuir isotherm parameters used to fit experimental data in adsorption of PCP to activated carbon.

\begin{tabular}{llcc}
\hline $\begin{array}{c}\text { Tween } 80 \\
\begin{array}{c}\text { concentration } \\
(\% \text { wt/vol })\end{array}\end{array}$ & $\mathrm{pH}$ & $\begin{array}{c}\text { Maximum } \\
\text { adsorbent } \\
\text { capacity } \\
(\mu \mathrm{mol} / \mathrm{g})\end{array}$ & $\begin{array}{c}\text { Dissociation } \\
\text { constant } \\
(\mu \mathrm{mol} / \mathrm{mL})\end{array}$ \\
\hline 0 & 5 & 1876.9 & $8.91 \times 10^{-3}$ \\
0 & 7 & 1284.9 & $6.33 \times 10^{-3}$ \\
0 & 8.5 & 884.7 & $5.28 \times 10^{-3}$ \\
0.002 & 7 & 245.2 & $7.82 \times 10^{-2}$ \\
0.004 & 7 & 347.4 & $2.04 \times 10^{-2}$ \\
\hline
\end{tabular}




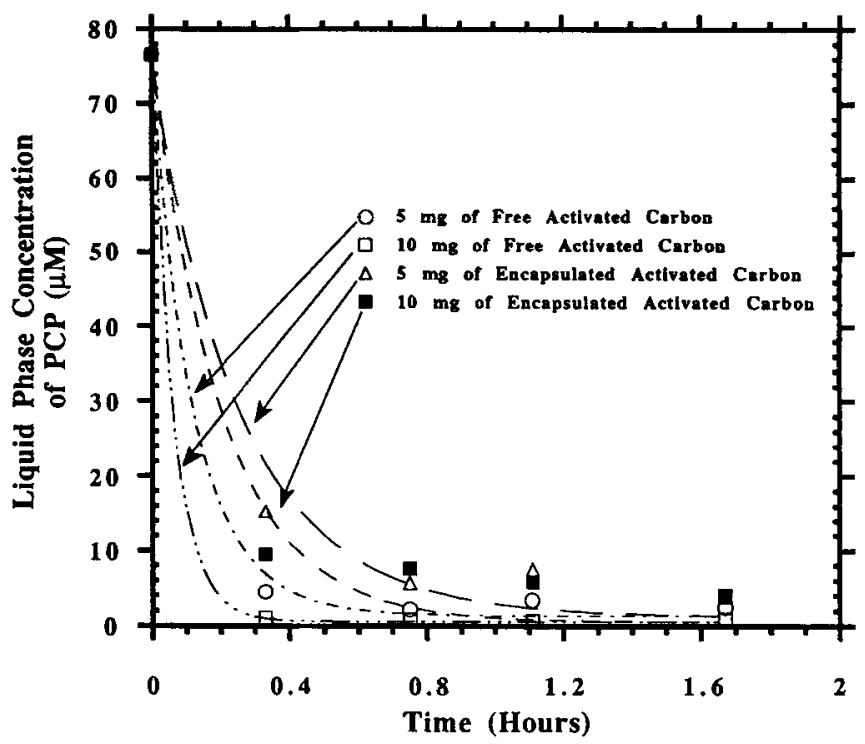

Figure 4. Batch PCP adsorption data compared to theoretical predictions; $[\mathrm{PCP}]_{0}=76.6 \mu M, R_{g}=3000 \pm 200 \mu \mathrm{m}, R_{g}-R_{c}=$ $200 \mu \mathrm{m}$. Curves are model predictions while the symbols are experimental measurements.

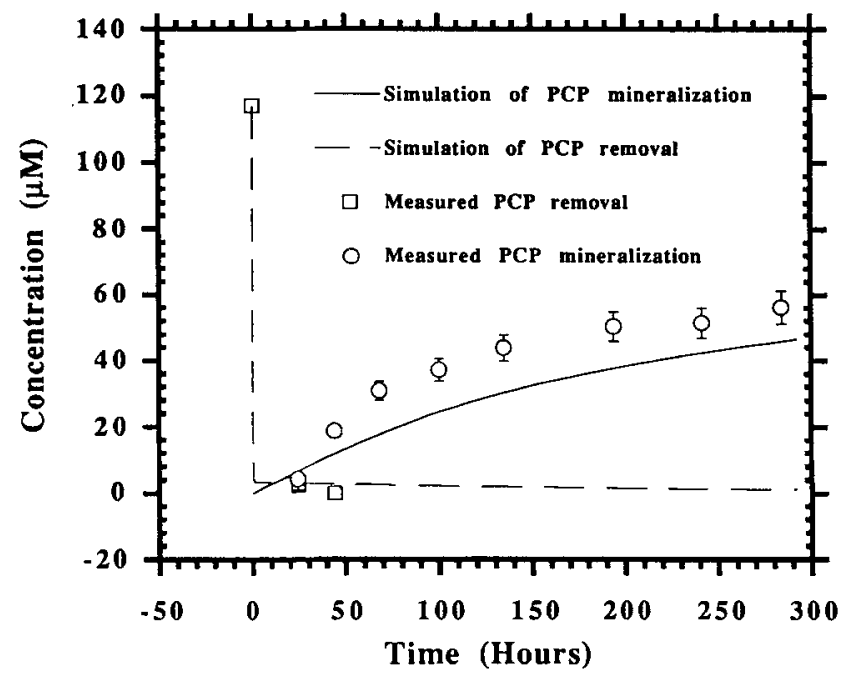

Figure 5. Removal and biodegradation of PCP by coimmobilized Arthrobacter and activated carbon compared to simulation results; $V_{A}=2.5 \mathrm{~mL}, W_{A}=5 \mathrm{mg}, X_{0}=0.0932\left(\mathrm{OD}_{560}\right), V_{b}=20 \mathrm{~mL}$, $[\mathrm{PCP}]_{0}=117 \mu M$, and $\mathrm{pH} 7$.

the coimmobilized system was not monitored in time. The cell growth model was checked against the growth of free cells and found to describe the cell concentration within the experimental error $( \pm 9 \%)$. The estimated kinetic parameters underpredict the mineralization rate of PCP over the 290-h period by approximately $20 \%$. This difference is primarily due to the simplicity of the presented metabolic model. Experimental data from the degradation of PCP by free cells in the absence of activated carbon (data not shown) revealed that the concentration of PCP decreased to zero from an initial concentration of $117 \mu M$ in a 45 -h period. During the same period, a material balance performed on ${ }^{14} \mathrm{CO}_{2}$ revealed that approximately half of the PCP $(\approx 53.8 \mu M)$ were mineralized. The remainder of PCP was either converted to metabolites which were further degraded in time, as evidenced by continued ${ }^{14} \mathrm{CO}_{2}$ release, or absorbed by the free cells such that measurement of extracellular PCP concentration was not indicative of total PCP present. It is also possible that the kinetic parameters calculated from free cells are slightly different in coimmobilized systems because of the effect of immobilized adsorbents. Since the model presented here for PCP adsorption, degradation, cell growth, and $\mathrm{CO}_{2}$ formation does not account for these phenomena, it is expected that discrepancies will exist between PCP mineralization rates predicted by the model and those measured experimentally. A more accurate model to describe the biological fate of PCP may improve the prediction of mineralization rate, but at the expense of added complexity and the further need for investigation of the mechanism of PCP degradation by this organism.

\section{MODEL PREDICTIONS}

\section{The Effect of Adsorbent Content}

The use of larger quantities of adsorbents in the coimmobilized systems leads to the reduction in PCP concentration, hence achieving a "clean solution" more quickly. However, the dependence of biodegradation on PCP concentration within the capsules leads to a lower overall rate of PCP mineralization.

Simulation results demonstrating the effect of adsorbent content on PCP mineralization in $290 \mathrm{~h}$ are displayed in Figure 6. The mineralization of PCP in a 290-h period decreased 55\% from 76 to $42 \mu M$ as the adsorbent content was increased twofold from 0.001 to $0.002 \mathrm{~g} / \mathrm{mL}$ at a maximum adsorbent capacity of

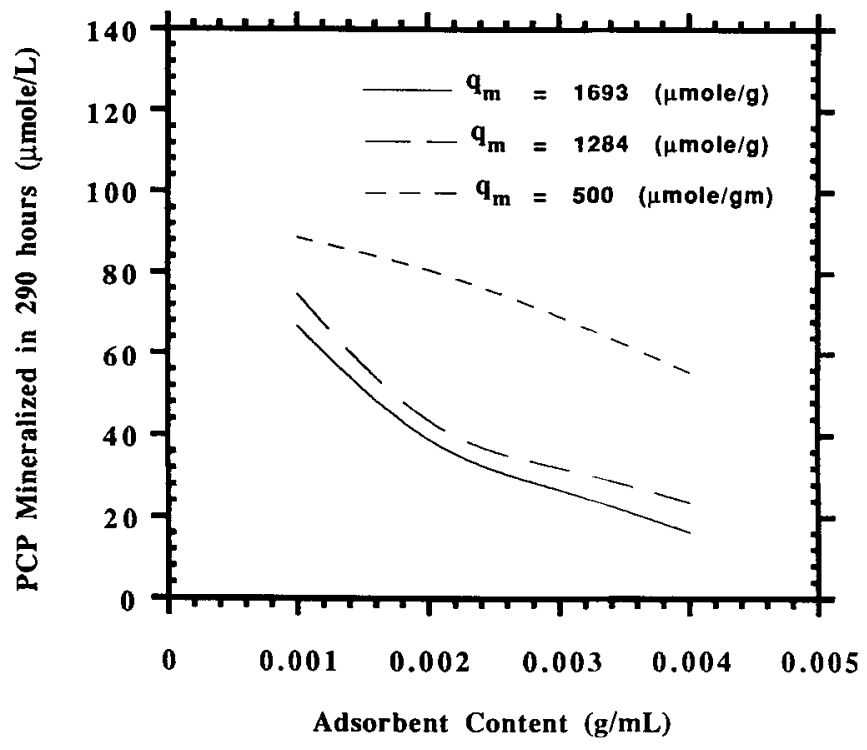

Figure 6. Effect of adsorbent content on PCP mineralization in $290 \mathrm{~h} ; K_{d}=6.33 \times 10^{-3} \mu \mathrm{mol} / \mathrm{mL}, S=0, R_{g}=3000 \mu \mathrm{m}, R_{g}-$ $R_{c}=200 \mu \mathrm{m}$. 
$1284 \mu \mathrm{mol} / \mathrm{g}$ and a dissociation constant of $6.33 \times$ $10^{-3} \mu \mathrm{mol} / \mathrm{mL}$. At a maximum capacity of $500 \mu \mathrm{mol} / \mathrm{g}$, the same twofold increase in adsorbent content from 0.001 to $0.002 \mathrm{~g} / \mathrm{mL}$ led to a $10 \%$ decrease in mineralization of PCP from 88.7 to $80.7 \mu M$. As the adsorbent content was increased, the adsorbent loading of PCP decreased, as did the PCP concentration inside the capsules. This lower PCP concentration translated into a lower degradation rate. A reduction in adsorbent capacity for the same adsorbent content increased the PCP concentration within the capsules and led to a greater biodegradation rate. As the adsorbent capacity was reduced, equivalent changes in adsorbent content had smaller effects on PCP mineralization. Figure 6 leads one to believe that the biodegradation rate of PCP can continue to increase as the adsorbent content is reduced to zero. This, however, is not entirely true. A high concentration of PCP will inhibit various organisms capable of degrading PCP. The adsorbent is necessary for quick contaminant removal and maintenance of contaminant concentration at nontoxic levels.

The effect of adsorbent content predicted by the model is accurate as long as the adsorbent particles do not significantly hinder the diffusion of contaminant within the capsule core. As the adsorbent content increases, the model will necessarily need to compute the effect of these particles on contaminant diffusion. Such computations have been previously demonstrated. ${ }^{13}$ It must be emphasized that the adsorbent content of the coimmobilized systems can only be increased within certain physical limits dictated by capsule size and preparation. As the adsorbent content is increased, there is physically less space available for cells and cell growth. These results suggest that for a given PCP removal, the adsorbent content must be optimized. Effects such as contaminant toxicity and substrate inhibition have not been modeled. The existence of such phenomena can influence the above results.

\section{The Effect of Adsorbent Type}

Since adsorbents other than activated carbon can be used in coimmobilized systems, the effect of using different adsorbents on the degradation of PCP was explored. Differences in adsorbent type were modeled as differences in capacity and dissociation constant, assuming adsorption equilibrium was always of the Langmuir form. Simulation results demonstrating the effect of adsorbent capacity on PCP mineralization are displayed in Figure 7. It was found that as the adsorbent capacity was decreased, the PCP mineralization increased. A twofold increase in adsorbent capacity from 250 to $500 \mu \mathrm{mol} / \mathrm{g}$ caused a $170 \%$ reduction in $\mathrm{PCP}$ mineralization in $290 \mathrm{~h}$, with $K_{d}$ held constant at $1 \times$ $10^{-3} \mu \mathrm{mol} / \mathrm{mL}$. When the dissociation constant was increased to $6.33 \times 10^{-3} \mu \mathrm{mol} / \mathrm{mL}$, the same twofold increase in adsorbent capacity from 250 to $500 \mu \mathrm{mol} / \mathrm{g}$

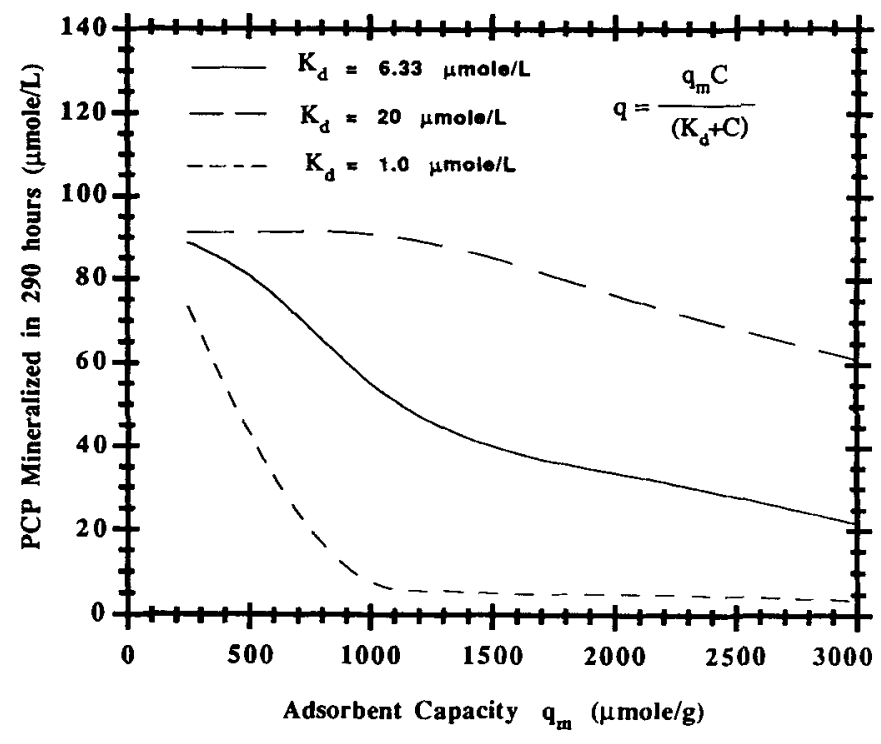

Figure 7. Effect of adsorbent capacity on PCP mineralization in $290 \mathrm{~h}$. Adsorbent content $0.002 \mathrm{~g} / \mathrm{mL}, S=0, R_{g}=3000 \mu \mathrm{m}, R_{g}-$ $R_{\mathrm{c}}=200 \mu \mathrm{m}$.

only reduced PCP mineralization by $11 \%$. When the dissociation constant was $20 \times 10^{-3} \mu \mathrm{mol} / \mathrm{mL}$, the twofold increase in adsorbent capacity caused a $1.2 \%$ reduction in PCP mineralization. The maximum PCP mineralization in $290 \mathrm{~h}$ always approached the same value as the adsorbent capacity was reduced.

The effect of dissociation constant on PCP mineralization is displayed in Figure 8 . When the dissociation constant was increased from $1 \times 10^{-3}$ to $1 \times 10^{-2} \mu \mathrm{mol} /$ $\mathrm{mL}$ at a constant capacity of $1693 \mu \mathrm{mol} / \mathrm{g}$ and a carbon content of $0.004 \mathrm{~g} / \mathrm{mL}$, PCP mineralization was increased 8.9-fold. As the carbon content was reduced to $0.002 \mathrm{~g} / \mathrm{mL}$, the same 10 -fold increase in dissociation constant increased PCP mineralization by 8.4 -fold. A further reduction in adsorbent content to $0.001 \mathrm{~g} / \mathrm{mL}$

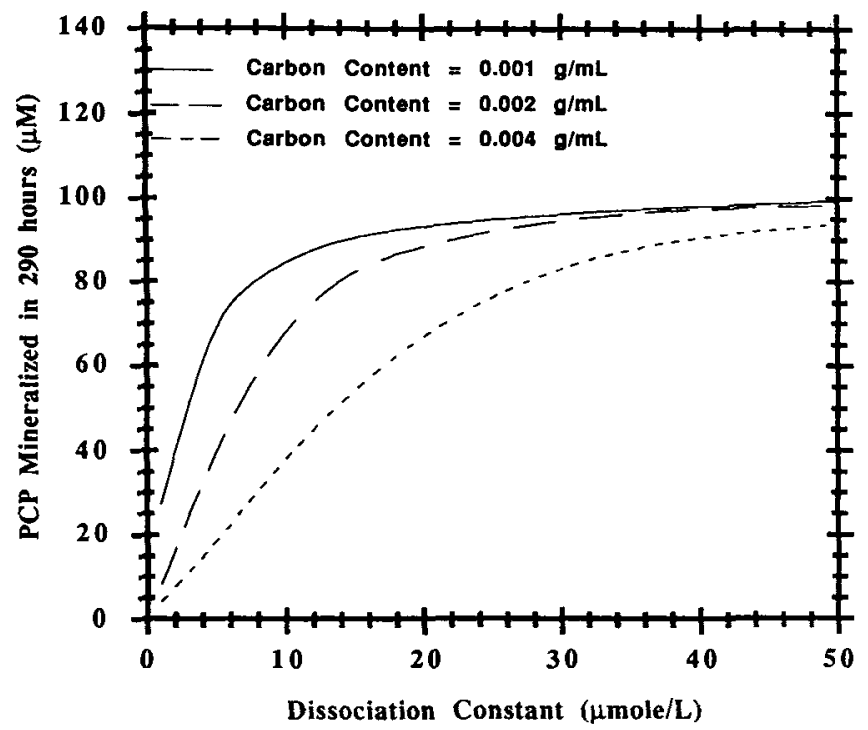

Figure 8. Effect of dissociation constant on PCP mineralization in $290 \mathrm{~h} ; q_{m}=1693 \mu \mathrm{mol} / \mathrm{g}, S=0, R_{g}=3000 \mu \mathrm{m}, R_{g}-R_{c}=200 \mu \mathrm{m}$. 
caused a 3.4-fold increase in PCP mineralization. It was found that for adsorbent-adsorbate systems with small dissociation constants $\left(K_{d} \leq 5 \times 10^{-3} \mu \mathrm{mol} / \mathrm{mL}\right)$, variations in $K_{d}$ had a greater effect on the absolute PCP mineralization when a smaller amount of adsorbent was used. The slope of PCP mineralization vs. $K_{d}$ increased as $K_{d}$ approached zero and was greatest for the smallest adsorbent content (Fig. 8). The dissociation constant is a measure of the affinity of an adsorbent-toxic compound complex to dissociate. The above results suggest using adsorbents with a strong affinity for the target compound sparingly, while adsorbents which bind the compound of interest loosely can be used in larger quantities without greatly reducing degradation rates.

\section{Biphasic Operation}

As demonstrated in the previous sections, a greater $q_{m}$ or smaller $K_{d}$ led to a lower PCP concentration within the solution, hence achieving a cleaner solution. However, lower PCP concentration in solution led to lower rates of degradation. Adsorbents with low $q_{m}$ or large $K_{d}$ achieved higher mineralization rates by retaining higher PCP concentration in solution for a longer period of time. If coimmobilized capsules were to be used in a pump and treat system, such as a fluidized or packed bed, low capacity or a large dissociation constant would require larger columns or higher adsorbent content to achieve the same effluent concentration for a given column service life.

As displayed in Figures 2 and 3, the equilibrium adsorption isotherm for PCP on activated carbon could be altered by changes in solution $\mathrm{pH}$ and addition of various amounts of surfactant Tween 80 . Theoretically, this makes possible the operation of a hybrid system with variable capacity and dissociation constant. Rapid adsorption could occur over a short period of time, even if conditions are unfavorable for degradation. The system, packed or fluidized bed, could then be isolated and an appropriate agent added in order to achieve conditions more favorable for biodegradation, i.e., $\mathrm{pH} \mathrm{7,} \mathrm{or} \mathrm{surfac-}$ tant addition.

In order to demonstrate this concept, simulations were conducted in which the adsorbent capacity and dissociation constant were 1876 and $8.91 \times 10^{-3} \mu \mathrm{mol} / \mathrm{mL}$, respectively. These values correspond to those measured at a $\mathrm{pH}$ of 5. The initial PCP concentration was $117 \mu M$, and the carbon content was $0.004 \mathrm{~g} / \mathrm{mL}$. Adsorption and degradation were allowed to proceed for $2 \mathrm{~h}$, at which point the liquid phase concentration of PCP was $2.8 \mu M$. At this time a change in solution $\mathrm{pH}$ was simulated by changing the adsorbent capacity and dissociation constant to those measured at $\mathrm{pH} 7$ or 8.5. In other simulations, the adsorbent capacity and dissociation constant were replaced by values measured with $0.002 \%$ and $0.004 \%$ Tween 80 (Table II). Adsorption equilibrium was quickly achieved, and the remainder of the operation proceeded under new conditions. Refer- ences in Figures 9 and 10 to various $\mathrm{pH}$ values and surfactant concentrations mean that the corresponding $q_{m}$ and $K_{d}$ values in Table II were used in the simulations. Such simulations cannot be interpreted as the effect of $\mathrm{pH}$ change or surfactant concentration on PCP mineralization by Arthrobacter since the effect of these variables on the microorganisms have not been modeled. However, the results can be interpreted as the effect of changes in adsorption behavior on PCP mineralization and would accurately predict the effect of changes in $\mathrm{pH}$ and surfactant concentration if the effect of such changes on the degrading organisms were known.

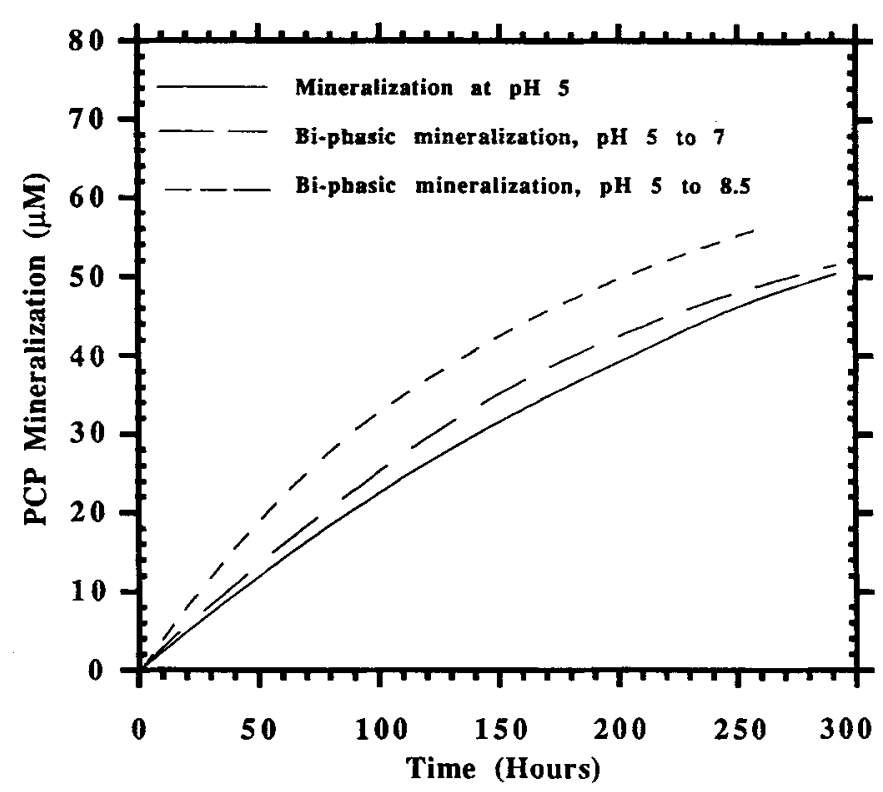

Figure 9. Comparison of predicted PCP mineralization at a $\mathrm{pH}$ of 5 with biphasic operations; pH 5 for the first two hours, then pH 7 or 8.5 .

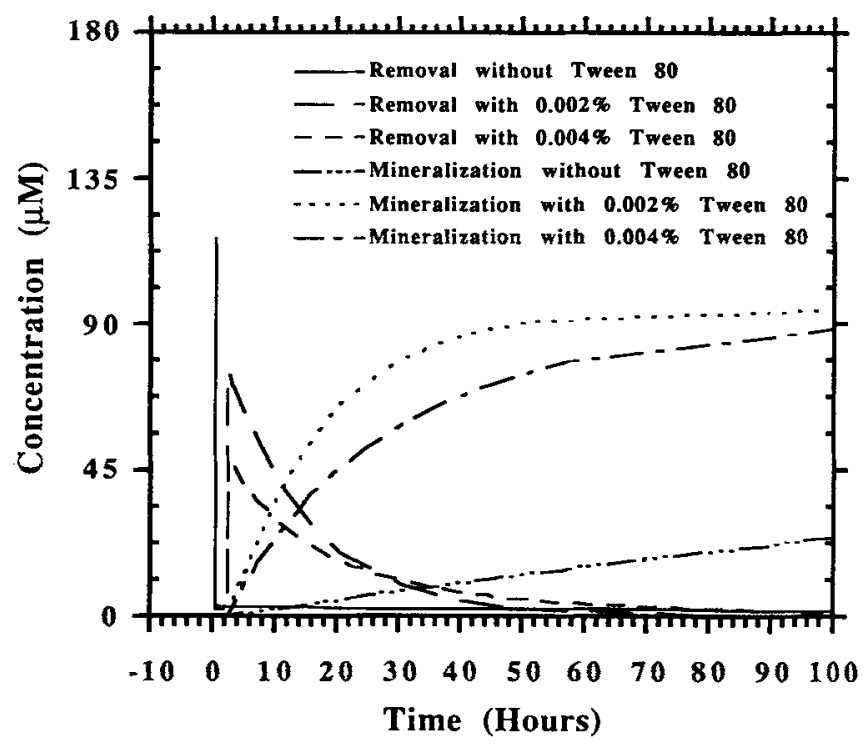

Figure 10. Comparison between PCP removal and mineralization at $\mathrm{pH}$ of 7 with biphasic operations at $\mathrm{pH} 7 ; S=0$ for the first $2 \mathrm{~h}$, the $S=0.002$ or $0.004 \% \mathrm{wt} / \mathrm{vol}$. 
The first set of simulations corresponding to changes in $q_{m}$ and $K_{d}$ resulting from $\mathrm{pH}$ variations are displayed in Figure 9. Pentachlorophenol mineralization over a 290-h period at a $\mathrm{pH}$ of 5 is compared to biphasic operations in which the solution $\mathrm{pH}$ was changed to 7.0 or 8.5 after $2 \mathrm{~h}$. Removal curves have not been displayed in Figure 9 because the curves were too close to distinguish on a graph of this size. Biphasic operation from a pH of 5 to 8.5 achieved the greatest PCP mineralization over $290 \mathrm{~h}$. When the adsorbent capacity and dissociation constant were changed to 884 and $5.28 \times$ $10^{-3} \mu \mathrm{mol} / \mathrm{mL}$ (corresponding to a $\mathrm{pH}$ of 8.5 ), PCP was released from the adsorbent into the coimmobilized capsules. The new adsorption isotherm resulted in the maintenance of a higher PCP concentration in solution and led to the mineralization of $19 \%$ more PCP in $290 \mathrm{~h}$.

The effect of adding various amounts of Tween 80 is displayed in Figure 10. After a 2-h adsorption period at a pH of 7.0, $q_{m}$ and $K_{d}$ were changed to those values corresponding to $0.002 \%$ and $0.004 \% \mathrm{wt} / \mathrm{vol}$ Tween 80 . The PCP concentration in solution rose to $73 \mu M$ following the addition of $0.002 \% \mathrm{wt} / \mathrm{vol}$ Tween 80 , while it rose to $51 \mu M$ following the addition of $0.004 \% \mathrm{wt} / \mathrm{vol}$ Tween 80 . Addition of $0.002 \% \mathrm{wt} / \mathrm{vol}$ Tween 80 resulted in the mineralization of $90 \%$ of the PCP initially present in a period of $50 \mathrm{~h}$. The addition of $0.004 \% \mathrm{wt} / \mathrm{vol}$ Tween 80 resulted in the mineralization of $67 \%$ of the PCP initially present in the same period of time. Without the addition of Tween 80 only $10 \%$ of the initial PCP was mineralized in $50 \mathrm{~h}$, and the system required approximately $400 \mathrm{~h}$ to mineralize $70 \%$ of the PCP.

\section{DISCUSSION}

Changes in the adsorption behavior of toxic organic contaminants such as PCP can significantly influence the degradation of these compounds by coimmobilized systems. The adsorption of PCP was found to occur on a time scale approximately 100 times shorter than the mineralization of PCP. Mathematical computations previously performed have shown that the time constant for diffusion of PCP into capsules with sizes ranging between 0.5 and $5 \mathrm{~mm}$ is of the same order of magnitude as the time constant for the adsorption process. This suggests that mineralization of PCP is the rate limiting step in the overall process. Pentachlorophenol mineralization is controlled by adsorption equilibrium rather than by adsorption rate, and changes in the equilibrium isotherm for PCP in this coimmobilized system can be expected to influence the mineralization rate.

Because both diffusion and adsorption occur much more quickly than the mineralization process, it is conceivable that the concentration of PCP within the coimmobilized system can be altered by changes in adsorption equilibrium. Internal or external agents that influence the adsorption of PCP onto coimmobilized adsorbents or the use of various adsorbents can achieve different PCP concentrations within the capsules. The ability to influence the concentration of contaminants within the coimmobilized capsules represents a great potential for degradation of toxic organic compounds. Highly toxic contaminants can be quickly removed from contaminated sites via adsorption. The concentration of such contaminants within coimmobilized systems can then be controlled, by the use of appropriate agents, such as surfactants, $\mathrm{pH}$, ionic strength, etc., in order to ensure minimum toxicity and maximum degradation rates.

The fate of the contaminant as well as the location of the biological reactions controlling its degradation are also of utmost importance. If all of the reactions involved in the degradation of the contaminant are intracellular, then degradation is a function of contaminant concentration in the aqueous region of the coimmobilized system. The immobilization of a larger quantity of cell mass may increase the overall mineralization rate. However, the involvement of extracellular enzymes, also capable of adsorbing to the coimmobilized adsorbents, could mean that the adsorbed contaminant may also participate in degradative reactions. ${ }^{10}$ In order to determine the impact of changes in adsorption behavior on mineralization, one may need to consider the adsorbent loading, extracellular enzyme concentration, adsorbent affinity for enzyme, as well as possible enzyme loss to deactivation or diffusion out of the capsules.

Another factor to be considered in designing coimmobilized systems is physical limitation. As more cells are coimmobilized within the capsule core, less volume will be available for coimmobilization of adsorbents, and vice versa. As the cell density and adsorbent content increase, these two variables may not be independent. It may also be necessary to account for oxygen transport and consumption or the effect of cells on the diffusion of components through the core in order to optimize such systems.

Other simulations were conducted to evaluate the sensitivity of PCP mineralization to mass transfer parameters such as capsule size, membrane thickness, and mass transfer coefficient. Within the size range of $0.5-5 \mathrm{~mm}$ and membrane thickness in the range of $200 \mu \mathrm{m} \pm 50 \%$, these two variables did not produce a significant change in PCP mineralization. Variations in external mass transfer coefficient between $5 \times 10^{-3}$ and $5 \times 10^{-6} \mathrm{~cm} / \mathrm{s}$ resulted in a $17 \%$ variation in PCP mineralization over $290 \mathrm{~h}$.

\section{CONCLUSIONS}

A coimmobilized system for degradation of PCP has been described. A mathematical model was developed to describe the interaction between the mass transfer, adsorption, and degradation of toxic contaminants in coimmobilized systems. The effect of various design variables were examined quantitatively on the mineral- 
ization of PCP. It was found that for a given PCP removal, the adsorbent content must be optimized. At constant adsorbent content, a reduction in adsorbent capacity or an increase in dissociation constant increased PCP mineralization. The external mass transfer resistance in the aqueous system studied was found to be negligible. It was found that variations in adsorbent capacity and dissociation constant consistent with those experimentally measured by addition of Tween 80 and $\mathrm{pH}$ changes caused significant changes in PCP mineralization. It was also demonstrated that the operation of a biphasic system in which conditions were initially favorable for adsorption could achieve a low PCP concentration in solution. Later, the conditions could be changed to favor degradation. The results presented in this study demonstrate the effect of adsorbents on mineralization of toxic organic contaminants. These results also demonstrate how changes in the equilibrium adsorption isotherm as a function of various variables can be utilized to increase mineralization without sacrificing contaminant removal.

We acknowledge financial support from the Environmental Protection Agency. J. E. Lin acknowledges the financial support of the Michigan Biotechnology Institute through a UM-MBI traineeship.

\section{NOMENCLATURE}

\begin{tabular}{|c|c|}
\hline$C$ & concentration $(\mu \mathrm{mol} / \mathrm{mL})$ \\
\hline$C_{i}$ & $\begin{array}{l}\text { concentration of species } i \text { in capsules } \\
(\mu \mathrm{mol} / \mathrm{mL})\end{array}$ \\
\hline$C_{b i}$ & $\begin{array}{l}\text { concentration of } i \text { in bulk solution } \\
(\mu \mathrm{mol} / \mathrm{mL})\end{array}$ \\
\hline$D$ & diffusion coefficient $\left(\mathrm{cm}^{2} / \mathrm{s}\right)$ \\
\hline$\varepsilon_{c i}$ & porosity of core for species $i$ \\
\hline$\varepsilon_{g i}$ & porosity of gel for species $i$ \\
\hline$\kappa_{1}$ & forward adsorption rate constant $(L / g \cdot h)$ \\
\hline$K_{d}$ & $\begin{array}{l}\text { dissociation constant of contaminant on } \\
\text { adsorbent, }=\kappa_{2} / \kappa_{1}(\mathrm{~mL} / \mu \mathrm{mol})\end{array}$ \\
\hline$K_{1}, K_{2}=K_{\text {growth }}, K_{3}$ & $\begin{array}{l}\text { combined reaction rate constants for } \mathrm{PCP} \\
\text { consumption, cell growth, and } \mathrm{CO}_{2} \text { pro- } \\
\text { duction }\left(1 / \mathrm{OD}_{560} \cdot \mathrm{h}, \mathrm{mL} / \mu \mathrm{mol} \cdot \mathrm{h} \text {, and }\right. \\
\left.\mu \mathrm{mol} \mathrm{CO}_{2} / \mu \mathrm{mol} \mathrm{PCP} \cdot \mathrm{OD}_{560} \cdot \mathrm{h}\right)\end{array}$ \\
\hline $\boldsymbol{K}_{c}$ & external mass transfer coefficient $(\mathrm{cm} / \mathrm{s})$ \\
\hline$n$ & $\begin{array}{l}\text { number of reactions each component is in- } \\
\text { volved in; in this model } n=1\end{array}$ \\
\hline$q$ & concentration in adsorbent phase $(\mu \mathrm{mol} / \mathrm{g})$ \\
\hline$q_{\max }$ & $\begin{array}{l}\text { maximum capacity of adsorbent according } \\
\text { to the Langmuir adsorption theory }(\mu \mathrm{mol} / \mathrm{g})\end{array}$ \\
\hline $\boldsymbol{R}$ & radial coordinate $(\mathrm{cm})$ \\
\hline$R_{c}$ & internal radius of gel membrane $(\mathrm{cm})$ \\
\hline$R_{g}$ & external radius of gel membrane $(\mathrm{cm})$ \\
\hline$R_{\text {ads }}$ & rate of $\mathrm{PCP}$ adsorption $(\mu \mathrm{mol} / \mathrm{mL} \cdot \mathrm{h})$ \\
\hline
\end{tabular}

$\begin{array}{ll}R X N & \text { rate of various reactions }(\mu \mathrm{mol} / \mathrm{mL} \cdot \mathrm{h}) \\ R X N_{x} & \text { rate of cell growth }\left(\mathrm{OD}_{560} / \mathrm{h}\right) \\ \rho_{\mathrm{g}} & \text { adsorbent content in capsules }(\mathrm{g} / \mathrm{mL}) \\ S & \text { surfactant concentration }(\% \mathrm{wt} / \mathrm{vol}) \\ t & \text { time }(\mathrm{h}) \\ \mu & \text { cell growth rate }\left(\mathrm{OD}_{560} / \mathrm{mL} \cdot \mathrm{h}\right) \\ V & \text { volume }(\mathrm{mL}) \\ W & \text { weight }(\mathrm{g}) \\ X & \text { concentration of cells }\left(\mathrm{OD}_{560}\right) \\ Y_{x / k}, Y_{\mathrm{CO}_{2 / x}} & \text { yield factors for conversion of PCP to cells } \\ & \text { and } \mathrm{CO}_{2}\left(\mathrm{OD}_{560} / \mu \text { mol PCP) and }(\mu \mathrm{mol}\right. \\ & \left.\mathrm{CO}_{2} / \mathrm{OD}_{560}\right)\end{array}$

\section{Subscripts}

$\begin{array}{ll}A, \text { ads } & \text { adsorbent } \\ B, b & \text { bulk solution } \\ i & \text { species } i \\ g, c & \text { gel membrane and capsule core } \\ R & \text { constant position (R) } \\ S & \text { constant surfactant concentration } \\ \mathrm{pH} & \text { constant pH } \\ t & \text { constant time } \\ l & \text { number of reactions } \\ 0 & \text { initial condition (i.e., at time } t=0)\end{array}$

\section{References}

1. Bailey, J. E., Ollis, D. F. 1986. Biochemical engineering fundamentals. 2nd edition. McGraw-Hill, New York.

2. Carnahan, B., Luther, H. A., Wilkes, J. O. 1969. Applied numerical methods. Wiley, New York.

3. Chandler, J. P., Hill, D. E., Spivey, H. O. 1972. Comput. Biomed. Res. 5: 515.

4. Edgehill, R.V., Finn, R. K. 1983. Appl. Environ. Microbiol. 45: 1122 .

5. Horstmann, B. J., Chase, H. A. 1989. Chem. Eng. Res. Des. 67: 243.

6. Kirk, T. K., Connors, W. J., Bleam, R. D., Hackett, W. F., Zeikus, J. G. Pro. 1975. Nat. Acad. Sci. USA. 72: 2515.

7. Langmuir, J. 1916. J. Am. Chem. Soc. 38: 2221.

8. Lin, J.-E., Hickey, R. F., Shen, G. J., Wang, H.Y. 1989. In: G. Lewandowski, P. Ardenante, and B. Blatzis (eds.), Biotechnology applications in hazardous waste treatment. Engineering Foundation, New York.

9. Lin, J.-E., Hickey, R. F., Wang, H.Y, 1991. Use of coimmobilized biological systems to degrade toxic organic compounds. Biotechnol. Bioeng. 38: 273.

10. Lin, J.-E. 1990. Biodegradation of toxic chemicals using the coimmobilization approach. PhD. Dissertation. The University of Michigan, Ann Arbor, MI.

11. Lin, J.-E., Hickey, R. F., Wang, H.Y. 1990. Biotechnol. Bioeng. 35: 1125 .

12. Nigam, S. C., Tsao, I-Fu, Sakoda, A., Wang, H.Y. 1988. Biotechnol. Techniq. 2: 217.

13. Nigam, S.C., Siahpush, A.R., Wang, H.Y. 1990. AICHE J. 36: 1239 .

14. Perry, R. H., Green, D. 1984. Chemical engineer's handbook. 6th edition. McGraw-Hill, New York. 